

Arqueología

\title{
El sitio Alero Cuevas, Pastos Grandes, Puna de Salta: Actualización y síntesis arqueológica de los cambios registrados a lo largo del Holoceno en perspectiva regional
}

\author{
The Alero Cuevas site, Pastos Grandes, Puna of Salta: Update and \\ archaeological synthesis of the changes recorded throughout \\ the Holocene in a regional perspective
}

Gabriel E. J. López*

*CONICET - Instituto de Arqueología, Facultad de Filosofía y Letras, Universidad de Buenos Aires, Argentina. Email: gabelope@yahoo.com

\begin{abstract}
Resumen
Se presenta una síntesis actualizada de la evidencia arqueológica del sitio Alero Cuevas, Pastos Grandes, Puna de Salta, a lo largo de la secuencia estratigráfica datada en el Holoceno temprano, medio y tardío. La información arqueológica proveniente de este sitio se discute en el marco regional de la cuenca de Pastos Grandes y de la Puna argentina. Esta perspectiva regional es útil para abordar diversos procesos de cambio ocurridos durante el Holoceno. En particular, el registro de Alero Cuevas contribuye al estudio de las variaciones relacionadas con la intensificación y domesticación de camélidos, la movilidad y la interacción en escala amplia, y los cambios tecnológicos, entre otros aspectos. Los resultados de la investigación permitieron analizar estas problemáticas a partir de distintos indicadores arqueológicos, en especial arqueofaunísticos y líticos. Los cambios más notables ocurrieron a partir del Holoceno medio final y se profundizaron durante el Holoceno tardío. Asimismo, se han detectado continuidades en las estrategias de uso del sitio en escala cronológica de largo plazo.
\end{abstract}

Palabras clave: Alero Cuevas; Puna; Evidencia arqueológica; Perspectiva regional.

\begin{abstract}
An updated synthesis of the archaeological evidence of the Alero Cuevas site, Pastos Grandes, Puna of Salta, is presented, along the stratigraphic sequence dated to the Early, Middle and Late Holocene. The archaeological information from this site is discussed within the regional framework of the Pastos Grandes basin and the Puna of Argentina. This regional perspective is useful to address various processes of change that occurred during the Holocene. In particular, the archaeological evidence of Alero Cuevas contributes to the study of the variations related to the intensification and domestication of camelids, mobility and interaction on a large scale, and technological changes, among other aspects. The results of the research allowed us to analyze these issues from different indicators, especially archaeofaunal and lithic ones. The most notable changes occurred from the late Middle Holocene and deepened during the Late Holocene. Likewise, continuities have been detected in the strategies of use of the site on a long-term chronological scale.
\end{abstract}

Keywords: Alero Cuevas, Puna; Archaeological evidence; Regional perspective.

\section{Introducción}

Diversas investigaciones en la Puna argentina han destacado que los abrigos rocosos constituyeron espacios frecuentes para la ocupación humana (López, 2013; Mondini et al., 2013; Pintar y Rodríguez, 2015; Yacobaccio et al., 2013, entre otros). En la Puna de Salta, se distingue un abrigo con una cronología extendida durante el Holoceno. Se trata de Alero Cuevas, localizado en un sector de quebradas de altura en la cuenca de Pastos Grandes (López, 2008). Este sitio es adecuado para el estudio de los procesos de cambio en escala de largo plazo, dado que las ocupaciones humanas se encuentran datadas en el Holoceno temprano, medio y tardío (López, 2013; López y Restifo, 2017).

En este trabajo se presenta una síntesis actualizada de la evidencia arqueológica recuperada en la secuencia estratigráfica y cronológica del sitio Alero Cuevas, con el objetivo de contribuir al análisis de los cambios ocurridos en una escala regional. Más claramente, se realiza una descripción breve del registro recabado en cada capa datada del sitio, como un aporte a la discusión de los procesos de cambio en las ocupaciones 
humanas de Pastos Grandes y, más generalmente, en la Puna argentina. En especial, el foco de estudio se centra en la intensificación y domesticación de camélidos, la movilidad e interacción macrorregional, y las variaciones artefactuales y tecnológicas. La información arqueológica presentada aquí, principalmente faunística y lítica, constituye un avance en el análisis de los temas mencionados previamente.

La cronología abarca desde las primeras ocupaciones humanas a comienzos del Holoceno temprano hasta contextos tardíos prehispánicos (ca. 10000 AP - 600 $A P)$. Al respecto, cabe destacar que toda la secuencia cronológica de Alero Cuevas corresponde a épocas prehispánicas. También es relevante señalar que si se considera la calibración de fechados del sitio, las primeras ocupaciones humanas superan los 11000 años cal AP.

En la Puna argentina, el Holoceno temprano (ca. 11000 $A P$ - $8000 \mathrm{AP}$ ) se ha caracterizado por la presencia de grupos humanos pequeños con alta movilidad residencial, en un ambiente más húmedo y con menor segmentación en parches de recursos que en la actualidad (Yacobaccio et al., 2017). Por el contrario, durante el Holoceno medio (ca. 8000 AP - 4000/3500 AP) el ambiente se habría segmentado fuertemente en parches de recursos puntuales y los grupos humanos habrían comenzado a reducir la movilidad residencial. En este contexto, se detectan procesos de intensificación y domesticación de camélidos, especialmente en el Holoceno medio final (ca. 6000/5500 AP - 4000/3500 AP) (Yacobaccio, 2001). Por intensificación se entiende el aumento de la producción y/o la productividad total por una unidad de tiempo y espacio, mientras que la domesticación implica la adaptación de una población de animales y/o plantas a los humanos y al ambiente por cambios genéticos que ocurren en varias generaciones y eventos de desarrollo ambientalmente inducidos (Yacobaccio y Vilá, 2002). Este marco fue propicio para cambios artefactuales y tecnológicos, reflejados en distintos sitios andinos (Aschero y Martínez, 2001; Hocsman, 2006; Hoguin, 2014; López y Restifo, 2017; Martínez, 2003; Moreno, 2011; Pintar, 2014; Ratto, 2006). A partir del
Holoceno tardío (desde ca. 4000/3500 AP en adelante), se desarrollaron nuevos nichos económicos en distintos ambientes locales de la Puna argentina. En particular, se han registrado economías basadas en el pastoreo de llamas (camélidos domesticados) y, en algunos casos, asociadas con prácticas agrícolas. De todas formas, la caza siguió siendo una actividad económica importante (Olivera, 1997). Asimismo, se registraron asentamientos con baja movilidad residencial que indicarían un mayor sedentarismo, mecanismos de interacción macrorregional relacionados con el transporte caravanero de llamas, y nuevas tecnologías como la cerámica (Olivera, 2012; Nielsen, 2013).

La secuencia de ocupaciones humanas del sitio Alero Cuevas, actualizada y sintetizada en este trabajo, realiza un aporte a la discusión de estos procesos en perspectiva regional.

\section{El sitio Alero Cuevas: estratigrafía, cronología y aspectos metodológicos}

La cuenca de Pastos Grandes comenzó a ser investigada sistemáticamente en el año 2004. Ese mismo año se detectó el sitio Alero Cuevas (López, 2008). Los años siguientes se realizaron distintos trabajos de excavación en el sitio con el objetivo de reconocer la variabilidad estratigráfica y cronológica. Se trata de un alero rocoso ubicado en la quebrada de Las Cuevas, en Pastos Grandes (Figura 1). De allí el nombre Alero Cuevas con el que fue denominado (López, 2008, 2013).

Este sitio se localiza a $4400 \mathrm{msnm}$ en un talud de la quebrada mencionada anteriormente, en el marco de un paisaje de alta calidad para la ocupación humana por la presencia de agua permanente, abundantes pasturas y camélidos silvestres, entre otros recursos. El agua proviene de los deshielos de los nevados de Pastos Grandes, principalmente el Quevar. La roca del alero es una toba dacítica que se reconoce fácilmente por su color blanquecino contrastante con el resto del paisaje. A su vez, se destaca por sus grandes dimensiones, con un ancho de 19,3 m en línea recta y más de $8 \mathrm{~m}$ en el

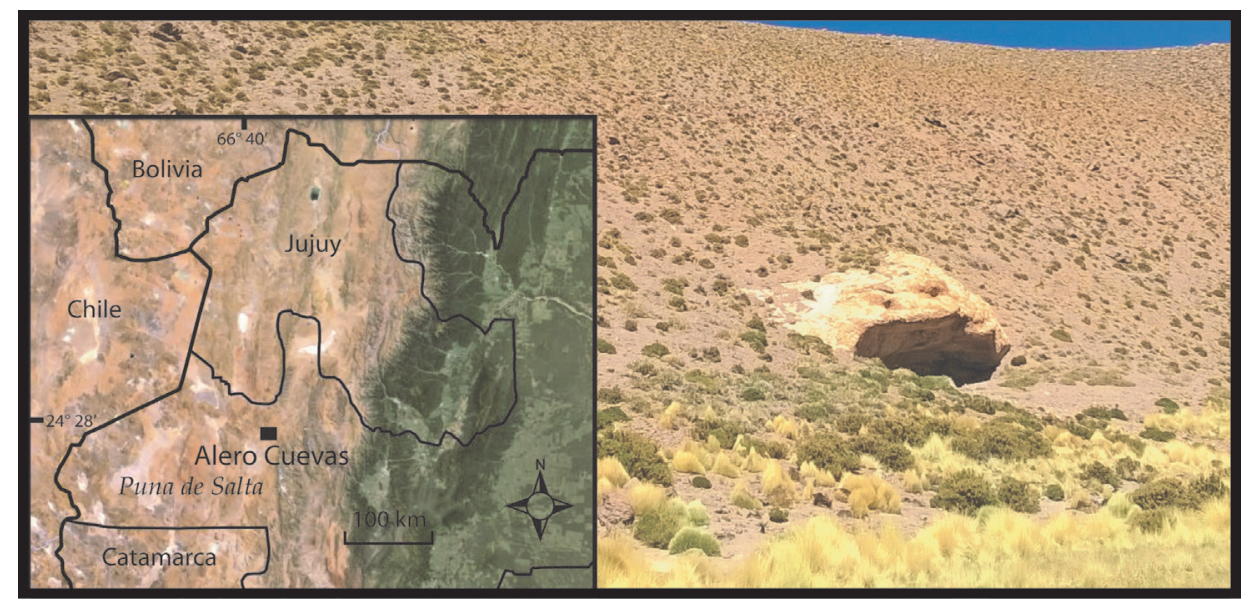

Figura 1. Imagen del sitio Alero Cuevas y ubicación en el contexto regional.

Figure 1. Image of the Alero Cuevas site and location in the regional context. 
sector más profundo a la línea de goteo.

Las investigaciones arqueológicas incluyeron la realización de 9 cuadrículas de $1 \times 1 \mathrm{~m}$, una extensión de cuadrícula de 1 x 0,5 m, y 4 sondeos de 0,5 x 0,5 m en diversos sectores del alero, totalizando $10,5 \mathrm{~m}^{2}$ de excavación (Figura 2). A partir de estos trabajos se reconoció cierta continuidad estratigráfica de la mayoría de las capas datadas y una potencia promedio de un metro. Las capas más representativas del sitio (Figura 2) tienen una matriz sedimentaria limosa, con variabilidad en la textura y el color, como así también en el contenido orgánico, arqueológico y cronológico. Con respecto a la cronología, se realizaron 14 fechados radiocarbónicos que indicaron ocupaciones humanas durante el Holoceno temprano, medio y tardío (López y Restifo, 2017) (Tabla 1). En el sector superficial se distingue la capa A, conformada por guano, que corresponde a momentos subactuales. En determinados sectores se reconocen algunas capas finas como la B (no fechada) y la $X$ (con un fechado de ca. 643 AP). La capa C1 se caracteriza por la presencia de una continuidad de gramíneas y sedimento con ceniza, fechada en ca. 2020 AP y ca. 2277 AP. En algunos sectores de las cuadrículas 1 y 2, se observan capas más finas por debajo de C1, aún no datadas. Por el contrario, la capa F2, fechada en ca. 4210 AP y ca. 5106 AP, presenta una continuidad en la mayor parte de las cuadrículas excavadas. Esta cronología corresponde a un contexto clave para estudiar los procesos de cambio relacionados con la intensificación y domesticación de camélidos a nivel regional en el Holoceno medio final. Por debajo se encuentra una capa más fina y pedregosa, denominada F3, que actualmente presenta cuatro fechados en el Holoceno medio inicial, entre ca. 6506 AP y ca. 7500 AP. Finalmente, la capa arqueológica más profunda es la F4, correspondiente al Holoceno temprano, con fechados entre ca. 8504 AP y ca. 9880 AP. Esta capa se encuentra sobre la roca de caja del alero que marca el final de la estratigrafía arqueosedimentaria (Figura 2).

En esta investigación, la unidad básica de análisis es el espécimen individual (sea un fragmento de hueso, un hueso entero, un instrumento lítico o un desecho de talla, entre otros), mientras que el conjunto arqueológico de cada capa es la unidad de mayor inclusividad dentro del sitio. Más precisamente, la información arqueológica se presenta ordenada a partir de la correspondencia con cada capa fechada. Esta metodología de análisis es coherente con el propósito del trabajo de caracterizar los cambios a lo largo del Holoceno en la secuencia del sitio. En concreto, se cuenta con 4 conjuntos principales de estudio: capa F4 del Holoceno temprano (9880-8504 AP), capa F3 del Holoceno medio inicial (7500-6506 AP), capa F2 del Holoceno medio final (5106-4210 AP), y capa C1 del Holoceno tardío (2277-2020 AP). La capa X (643 AP) no se consideró en este trabajo por su escasa representación en el sitio, lo cual impide una comparación adecuada con la evidencia de los otros conjuntos.
Figura 2. El sitio Alero Cuevas. Planta con la ubicación de las unidades de excavación (arriba) y perfil estratigráfico con las capas datadas (abajo).

Figure 2. The Alero Cuevas site. Plan with the location of the excavation units (top) and stratigraphic profile with dated layers (bottom).
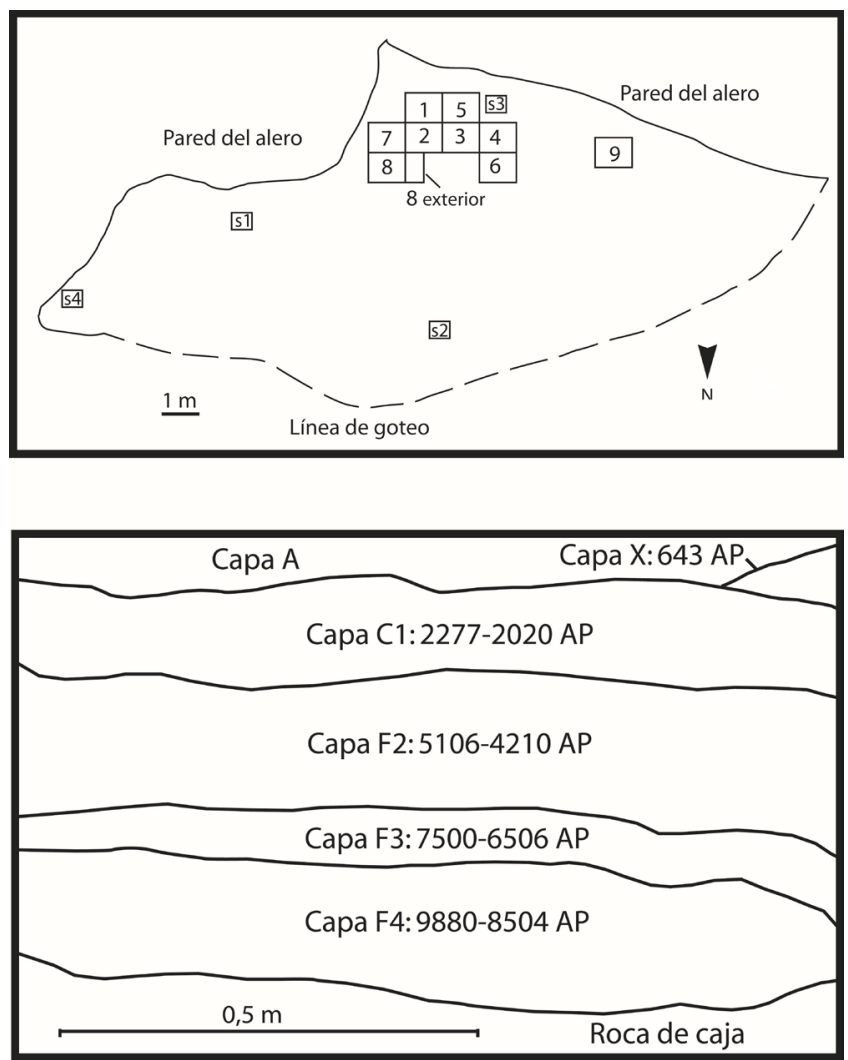

\section{Evidencia arqueológica del Holoceno temprano, medio y tardío en el sitio Alero Cuevas}

\section{Conjunto de la capa F4 (9880-8504 AP)}

Los resultados de los análisis en los conjuntos de la secuencia estratigráfica de Alero Cuevas permitieron distinguir cambios y continuidades en los principales indicadores arqueofaunísticos y líticos (Tabla 2). En primer lugar, se presenta la información de la capa F4, la más temprana del sitio. La sumatoria de materiales faunísticos y líticos es de 13265 especímenes.

Las arqueofaunas comprenden un conjunto de 7831 especímenes en total, de los cuales se identificaron 1186 a nivel taxonómico de familia. En este punto, hay que señalar la importancia de la explotación de camélidos por sobre otros taxones. Los camélidos representan el 91,4\% en NISP, mientras que los chinchíllidos solamente el 8,4\% (Orsi, 2018). Entre los camélidos, la osteometría permitió reconocer especímenes de tamaños más pequeños, que corresponderían a vicuñas, y especímenes más grandes, que pertenecerían a guanacos (ver López y Orsi, 2019). En relación con los guanacos, es importante mencionar que se detectaron tamaños más grandes que en la actualidad, lo cual es coherente con la evidencia regional que indica 


\begin{tabular}{|c|c|c|c|c|}
\hline Capa & Laboratorio & $\begin{array}{c}\text { Fechado radiocarbónico en } \\
\text { años AP }\end{array}$ & $\begin{array}{c}\text { Fechado calibrado, } 2 \\
\text { sigmas, años AP }\end{array}$ & $\begin{array}{l}\text { Muestra } \\
\text { fechada }\end{array}$ \\
\hline$x$ & AA 66544 & $643 \pm 35$ & $654-539$ & Vegetal \\
\hline C1 & LP- 1671 & $2020 \pm 60$ & $2090-1750$ & Vegetal \\
\hline C1 & AA90385 & $2277 \pm 54$ & $2348-2110$ & Óseo \\
\hline F2 & LP- 1655 & $4210 \pm 70$ & $4858-4450$ & Óseo \\
\hline F2 & AA90383 & $5106 \pm 68$ & 5986-5605 & Carbón \\
\hline F3 & AA 71137 & $6506 \pm 58$ & $7505-7261$ & Óseo \\
\hline F3 & LP- 1759 & $6510 \pm 80$ & $7565-7175$ & Carbón \\
\hline F3 & LP- 3214 & $7400 \pm 80$ & $8356-8016$ & Carbón \\
\hline F3 & LP- 3220 & $7500 \pm 160$ & 8589-7967 & Carbón \\
\hline F4 & AA71135 & $8504 \pm 52$ & $9543-9321$ & Carbón \\
\hline F4 & AA 71136 & $8838 \pm 52$ & $10150-9560$ & Carbón \\
\hline F4 & LP- 3226 & $9280 \pm 140$ & $11068-9970$ & Carbón \\
\hline F4 & LP- 1736 & $9650 \pm 100$ & $11212-10664$ & Carbón \\
\hline F4 & LP- 3236 & $9880 \pm 100$ & $11715-10819$ & Carbón \\
\hline
\end{tabular}

los desechos de talla $(98,2 \%$ del conjunto), en su mayoría de tamaños pequeños y muy pequeños (sensu Aschero, 1983). Entre los instrumentos se reconocen puntas de proyectil cronológicamente diagnósticas o tiempo-sensitivas relevantes para la discusión regional (Figura 3 A). Se hace referencia a las puntas triangulares apedunculadas de base recta $(n=11)$, confeccionadas mayoritariamente en obsidiana y con longitudes variables entre $31,6 \mathrm{~mm}$ y $21,5 \mathrm{~mm}$ (López y Restifo, 2017). Estos artefactos son recurrentes en el Holoceno temprano a nivel macrorregional (Núñez, 1992). En términos generales, el conjunto lítico indica una tendencia a estrategias de minimización del tiempo o expeditivas, tanto por la utilización de formas base (lascas) con baja inversión de energía, como por la predominancia de formatización unifacial con retoque marginal (sensu Aschero, 1983) y bajos niveles de estandarización morfológica, salvo en las puntas de proyectil (Restifo, 2019).

En relación con las materias primas representadas, el conjunto

Tabla 1. Fechados radiocarbónicos en el sitio Alero Cuevas.

Table 1. Radiocarbon dates at the Alero Cuevas site.

un decrecimiento del tamaño de estos animales a lo largo del Holoceno (Mengoni Goñalons y Yacobaccio, 2006).

El perfil etario de los camélidos mostró un predominio de los elementos óseos correspondientes a maduros/ adultos (57,5\%), mientras que los de nonatos/neonatos e inmaduros/subadultos representaron el $15,5 \%$ y el $26,9 \%$, respectivamente. Asimismo, se contabilizaron las distintas partes esqueletarias de los camélidos, con un predominio de las apendiculares (80,5\% en MNE). Los especímenes con marcas antrópicas en estos recursos representan el 19,5\%; otros indicadores tafonómicos como las marcas no antrópicas o la meteorización se encuentran en baja frecuencia en este conjunto (para más detalle ver Orsi, 2018). En consecuencia, se destaca que el agente antrópico fue el principal formador del registro.

Respecto del material lítico, la muestra total es de 5434 especímenes (Restifo, 2019), con un predominio de de instrumentos y desechos de talla registra un $67 \%$ de obsidianas, mientras que el porcentaje restante se distribuye entre andesitas, cuarcitas y otras rocas locales (Restifo, 2019). Cuando se distinguen rocas locales se hace mención a las materias primas que proceden de la cuenca de Pastos Grandes, en un rango no mayor a 30 $\mathrm{km}$ de distancia del sitio a la fuente. En el caso de Alero Cuevas, todas las obsidianas son no locales, mientras que las andesitas y las cuarcitas son locales, con fuentes ubicadas entre 10 y $20 \mathrm{~km}$ de distancia del sitio. Las obsidianas más comunes en esta capa son las de Quirón, una fuente localizada a aproximadamente $40 \mathrm{~km}$ de Alero Cuevas. Los análisis por fluorescencia de rayos $X(F R X)$, realizados en la Universidad de Missouri por el Dr. Michael Glascock, permitieron distinguir obsidianas procedentes de 6 fuentes distintas en este conjunto. Específicamente, 16 muestras indicaron la procedencia desde las fuentes de Quirón (Salta), Tocomar (Salta), Archibarca (Catamarca), Ona (Catamarca), Salar del Hombre Muerto (límite entre Catamarca y Salta) y Zapaleri (límite entre Jujuy, Chile y Bolivia) (López, 2020). En algunos casos, como Zapaleri, la distancia a Alero Cuevas es cercana a los 300 km lineales. La variabilidad de fuentes de distintos sectores de la Puna 
(norte, sur y oeste) y la distancia implicada en cada caso indican la importancia que tuvieron los mecanismos de movilidad y/o interacción para los grupos humanos que ocuparon Alero Cuevas durante el Holoceno temprano.

\section{Conjunto de la capa F3 (7500-6506 AP)}

Se trata de un conjunto más reducido, con una menor frecuencia de materiales que en la capa anterior. En este caso, el registro predominante (fauna y lítico) cuenta con 2288 especímenes estudiados hasta el momento. La disminución en la frecuencia de hallazgos arqueológicos se relacionaría con ocupaciones humanas menos recurrentes durante este lapso del Holoceno medio inicial, en comparación con el Holoceno temprano. Esta particularidad se refleja en un bajo espesor de esta capa, a diferencia de la anterior (Figura 2).

El conjunto arqueofaunístico está compuesto de 2085 especímenes en total, de los cuales se identificaron 389 a nivel taxonómico de familia. Entre estos últimos predominan claramente los camélidos (94,6\% en NISP), con un leve aumento con respecto a la capa anterior (Orsi, 2018). A nivel osteométrico, se observaron algunos valores de falanges primeras y segundas que corresponderían a guanacos (ver López y Orsi, 2019). Al mismo tiempo, se detectaron valores similares al tamaño de vicuñas. Dentro del conjunto de los camélidos, el perfil etario se parece al del Holoceno temprano, con un predominio aún mayor de los elementos de animales maduros/adultos $(61,8 \%)$ y valores menores de inmaduros/juveniles $(23,7 \%)$ y nonatos/neonatos (14,5\%). Las partes esqueletarias representadas en los camélidos siguieron el mismo patrón del Holoceno temprano, con la presencia de casi todas las unidades anatómicas pero con un porcentaje mucho mayor de las apendiculares, cuantificadas en MNE (81,8\%). En relación con los especímenes de camélidos con marcas antrópicas, se registra un porcentaje mayor que en la capa F4 (23,4\%), aunque el aumento no es pronunciado. Las demás variables tafonómicas, vinculadas a procesos y agentes no antrópicos, no tuvieron una incidencia importante en la formación del conjunto (para más detalle ver Orsi, 2018).

El registro lítico se compone de una muestra más reducida ( $\mathrm{N}=203)$ (Restifo, 2013), en su mayoría desechos de talla $(96,05 \%)$ de tamaños pequeños y muy pequeños (sensu Aschero, 1983). Los instrumentos diagnósticos o tiempo-sensitivos corresponden principalmente a puntas de proyectil o preformas lanceoladas mediano-grandes (Figura 3 B) y a una punta fragmentada de forma elongada con pedúnculo destacado (López y Restifo, 2017). En líneas generales, no se evidencia un incremento en la inversión de energía ni cambios tecnológicos observables. Al respecto, la forma base de los instrumentos y el análisis de los desechos de talla permiten sostener la ausencia de tecnología de hojas y la predominancia de tecnología de lascas (Restifo, 2013). Las materias primas, al igual que en la capa anterior, presentan un alto porcentaje de obsidianas (68\%). A partir de las características macroscópicas, se observa una preponderancia de la obsidiana de la fuente de Quirón.

\section{Conjunto de la capa F2 (5106-4210 AP)}

La muestra estudiada en esta capa indica un incremento importante de la frecuencia de materiales arqueológicos con respecto a la capa F3. Entre el material faunístico y lítico, el conjunto se compone de 3849 especímenes. Este incremento refleja un aumento en la señal antrópica durante este lapso, correspondiente al Holoceno medio final.

El registro arqueofaunístico consta de 3131 especímenes en total, mientras que la identificación taxonómica a nivel de familia permitió dar cuenta de 744 especímenes. En este conjunto, también predominan los camélidos con un 94,3\% en NISP (Orsi, 2018). Lo más novedoso ocurre en relación con la variabilidad específica dentro de los camélidos. Si bien la osteometría realizada en este conjunto detectó diversos elementos que corresponderían a vicuñas, también se registraron especímenes de mayor tamaño (principalmente falanges y una escápula) que podrían indicar la presencia de camélidos domesticados y/o en proceso de domesticación (ver López y Orsi, 2019). Esta interpretación se basa tanto en el tamaño grande de estos elementos como en información comparativa proveniente de sitios de los Andes centro sur, que muestra resultados similares relacionados con la domesticación a lo largo de esta cronología (Mengoni Goñalons y Yacobaccio, 2006).

Otro cambio relevante en la fauna se observa en el perfil etario de los camélidos. A diferencia de las dos capas previamente analizadas, en este conjunto, los elementos óseos de subadultos aumentan notablemente, distribuidos en $28,8 \%$ de inmaduros/juveniles y $26,3 \%$ de nonatos/ neonatos. Por el contrario, los elementos de maduros/ adultos disminuyen fuertemente, con un porcentaje total de $44,9 \%$. Se ha planteado que estos indicadores, sumados a un mayor estado de fragmentación en distintas variables de los huesos de camélidos, podrían relacionarse con procesos de intensificación en la explotación de estos recursos (ver López y Orsi, 2019; Orsi, 2018). Esta interpretación se vincula también con los cambios tecnológicos registrados en esta capa (ver más adelante). En relación con la representación de partes esqueletarias, no se registran cambios con respecto a los otros conjuntos. De forma similar, se evidencian todas las partes anatómicas del esqueleto de los camélidos con una alta proporción de las apendiculares (81,5\% en MNE). Tampoco se registran variaciones importantes en los porcentajes de especímenes de camélidos con marcas antrópicas $(23,9 \%)$ ni en otros indicadores tafonómicos no antrópicos, los cuales muestran baja incidencia general (para más detalle ver Orsi, 2018).

Respecto del conjunto lítico, se observan algunos cambios 
notorios en relación con las otras capas analizadas. La muestra estudiada se compone de 718 especímenes (Restifo, 2013), con un predominio de los desechos de talla (95,5\%), mayormente de tamaños pequeños y muy pequeños (sensu Aschero, 1983). Un detalle particular de esta capa es la representación de un núcleo de hojas en asociación con artefactos denominados como lanceolados unifaciales, Saladillo o lanceolados sobre hojas, entre otros nombres (Figura 3 C, D). Se trata de instrumentos representados en contextos del Holoceno medio final, tanto en Alero Cuevas $(n=11)$ como en otros sitios de la Puna argentina (López y Restifo, 2017). Estos artefactos presentan forma base de hojas, morfología lanceolada, talla predominantemente unifacial y materia prima local como andesita y cuarcita. La proliferación de hojas en esta capa y su ausencia en otras cronologías del sitio, se ha vinculado con un cambio tecnológico regional asociado con procesos de intensificación (López y Restifo, 2012; ver discusión más adelante).

En relación con el uso de materias primas, en la totalidad del conjunto lítico, se detecta una representación proporcional de las locales y las no locales, 49,4\% y $50,6 \%$ respectivamente. Este indicador muestra una fuerte variación con respecto a las otras capas, en las cuales predominan ampliamente las obsidianas. En otras palabras, se evidencia un aumento relevante de las materias primas locales (e.g. andesitas y cuarcitas) y una disminución de las no locales (obsidianas) (Restifo, 2013). Entre las obsidianas predominan las de Quirón, pero por FRX también se determinó la presencia de la fuente de Tocomar (López, 2020). Los atributos macroscópicos indican una menor variabilidad de obsidianas que en el Holoceno temprano, pero se espera ampliar el análisis por FRX en los conjuntos del Holoceno medio con el objetivo de precisar este aspecto.

\section{Conjunto de la capa C1 (2277-2020 AP)}

La muestra analizada hasta el momento tiene 2790 especímenes de fauna y lítico. Como particularidad, la capa C1 presenta una excelente preservación del material orgánico, no solo de los huesos sino de distintos elementos vegetales como semillas, frutos y madera, entre otros. Estas características pueden deberse a su hallazgo entre una amplia camada de gramíneas y sedimento carbonoso que protegió y preservó diferencialmente esta clase de material.

El conjunto arqueofaunístico analizado comprende 2196 especímenes en total, de los cuales fueron identificados 639 especímenes a nivel taxonómico de familia. Al igual que en las otras capas, los camélidos se encuentran representados en un porcentaje muy alto $(94,6 \%)$. Entre ellos, la osteometría permitió distinguir tamaños más pequeños correspondientes a vicuñas $(n=14) y$, en menor medida, tamaños más grandes, que corresponderían a llamas $(n=3)$. En este contexto cronológico se espera una consolidación de las economías pastoriles en la
Puna, por lo cual la presencia de llamas es claramente factible. Sin embargo, no puede dejar de mencionarse un predominio de especímenes de vicuñas, dado que prevalecen los tamaños pequeños, principalmente en las



Figura 3. Artefactos recuperados en las excavaciones de Alero Cuevas. A. Punta triangular apedunculada hallada en la capa F4 del Holoceno Temprano. B. Punta lanceolada procedente de la capa F3 del Holoceno medio inicial. C. Núcleo de hojas de la capa F2 del Holoceno medio final. D. Artefactos lanceolados unifaciales o Saladillo de la capa F2 del Holoceno medio final. E. Puntas triangulares pedunculadas de la capa C1 del Holoceno tardío. F. Artefactos de madera de la capa C1 del Holoceno tardío. G. Fragmento de cuenta de valva procedente del Océano Pacífico, hallado en la capa C1 del Holoceno tardío. H. Vasija de cerámica recuperada en excavación (Holoceno tardío).

Figure 3. Artifacts recovered from the Alero Cuevas excavations. A. Triangular unstemmed point found in Early Holocene layer F4. B. Lanceolate point from the F3 layer of the early Middle Holocene, C. Blade core from the F2 layer of the final Middle Holocene. D. Unifacial lanceolate or Saladillo artifacts from the F2 layer of the final Middle Holocene. E. Triangular stemmed points of Late Holocene layer C1. F. Late Holocene layer $C 1$ wood artifacts. G. Shell bead fragment from the Pacific Ocean, found in Late Holocene layer C1. H. Ceramic vessel recovered in excavation (Late Holocene). 
falanges primeras que fueron medidas. Este resultado es concordante con el uso de Alero Cuevas como un sitio desde el que se realizaba la caza de camélidos silvestres, estrategia económica que siguió siendo importante en contextos pastoriles. En relación con el perfil etario del conjunto de camélidos, el estudio no se encuentra concluido. Hasta el momento se pudo determinar una representación bastante proporcional de especímenes fusionados $(47,2 \%)$ y no fusionados $(52,7 \%)$, aunque la continuidad de los análisis será fundamental para abordar esta problemática. Respecto de las partes esqueletarias de los camélidos, como en el resto de los conjuntos, se evidencia una presencia de los distintos elementos anatómicos. En este caso, las partes apendiculares, aunque son predominantes, se encuentran en un porcentaje menor que en las otras capas $(57,8 \%$ en MNE). Asimismo, los especímenes de camélidos con marcas antrópicas presentan un porcentaje de 16,7\%. En general, salvo las marcas de roedores que llegan al $20 \%$, no se observa una incidencia importante de otras variables tafonómicas no antrópicas (para más detalle ver López, 2008). De todas formas, se profundizarán los análisis tafonómicos en esta capa a partir de nuevas muestras, para avanzar en el estudio del impacto de los roedores en parte del conjunto. Más allá de estos aspectos, la acción antrópica fue fundamental en la formación y acumulación del registro analizado.
El material lítico se compone de 594 especímenes, con una clara mayoría de los desechos de talla $(93,4 \%)$ de tamaños pequeños y muy pequeños (sensu Aschero, 1983). En concordancia con el predominio de huesos de vicuñas, se recuperaron 14 puntas de proyectil (Mercuri, 2014). Las clases diagnósticas de cronología comprenden las puntas triangulares pequeñas con pedúnculo (Figura 3 E). Esta morfología prolifera en el Holoceno tardío a nivel regional. Salvo las puntas, el resto del conjunto tiende a una baja inversión de energía, con retoques marginales, escasa estandarización y ausencia de tecnologías más complejas como las hojas, dado que la forma base de los instrumentos corresponde a lascas (Mercuri, 2014). La materia prima predominante es la obsidiana (69\%), mayoritariamente de Quirón. Este aspecto evidencia un aumento notable de las materias primas no locales en comparación con la capa F2 del Holoceno medio final. Entre las obsidianas presentes en esta capa, los análisis por FRX permitieron determinar, además de Quirón, las fuentes de Archibarca y Zapaleri (Mercuri y Restifo, 2014). La diversidad de materiales alóctonos no solamente se limita a la obsidiana sino también a distintos elementos orgánicos.

Entre la camada de gramíneas, presumiblemente usada para acondicionar el suelo dentro de un espacio doméstico, se han obtenido otros materiales relevantes

\begin{tabular}{|c|c|c|}
\hline $\begin{array}{c}\text { Sitio Alero } \\
\text { Cuevas: } \\
\text { Capa/cronología }\end{array}$ & Conjunto arqueofaunístico & Conjunto lítico \\
\hline $\begin{array}{c}\text { Capa F4/Holoceno } \\
\text { temprano (ca. } \\
9880-8500 \mathrm{AP})\end{array}$ & $\begin{array}{l}\text { Alta representación de camélidos; } \\
\text { tamaños de especímenes } \\
\text { asignados a guanacos grandes y } \\
\text { vicuñas; predominancia de } \\
\text { camélidos maduros/adultos }\end{array}$ & $\begin{array}{l}\text { Artefactos tiempo-sensitivos: Puntas } \\
\text { triangulares apedunculadas de base recta; } \\
\text { forma base de lascas; preponderancia de } \\
\text { estrategias de minimización del tiempo o } \\
\text { expeditivas; predominio de materias } \\
\text { primas no locales ( } 6 \text { fuentes de obsidiana } \\
\text { representadas) }\end{array}$ \\
\hline $\begin{array}{c}\text { Capa F3/Holoceno } \\
\text { medio inicial (ca. } \\
7500-6500 \text { AP) }\end{array}$ & $\begin{array}{l}\text { Alta representación de camélidos; } \\
\text { tamaños de especímenes } \\
\text { asignados a guanacos y vicuñas; } \\
\text { predominancia de camélidos } \\
\text { maduros/adultos }\end{array}$ & $\begin{array}{l}\text { Artefactos tiempo-sensitivos: Puntas } \\
\text { bifaciales lanceoladas/elongadas medianas } \\
\text { y grandes; forma base de lascas; } \\
\text { preponderancia de estrategias de } \\
\text { minimización del tiempo o expeditivas; } \\
\text { predominio de materias primas no locales } \\
\text { (obsidianas) }\end{array}$ \\
\hline $\begin{array}{l}\text { Capa F2/Holoceno } \\
\text { medio final (ca. } \\
5100-4200 \text { AP) }\end{array}$ & $\begin{array}{l}\text { Alta representación de camélidos; } \\
\text { tamaños de especímenes } \\
\text { asignados a vicuñas y llamas (o } \\
\text { camélidos en proceso de } \\
\text { domesticación); predominancia de } \\
\text { camélidos inmaduros /subadultos }\end{array}$ & $\begin{array}{l}\text { Artefactos tiempo-sensitivos: Instrumentos } \\
\text { Saladillo (lanceolados unifaciales); } \\
\text { presencia de tecnología de hojas; } \\
\text { estrategias de maximización de recursos } \\
\text { asociadas a la tecnología de hojas; } \\
\text { aumento de materias primas locales }\end{array}$ \\
\hline $\begin{array}{c}\text { Capa C1/Holoceno } \\
\text { tardío (ca. } 2000 \\
\text { AP) }\end{array}$ & $\begin{array}{l}\text { Alta representación de camélidos; } \\
\text { tamaños de especímenes } \\
\text { asignados a vicuñas (mayoritarias) } \\
\text { y llamas; tendencia al equilibrio } \\
\text { entre especímenes no fusionados } \\
\text { y fusionados }\end{array}$ & $\begin{array}{l}\text { Artefactos tiempo-sensitivos: Puntas } \\
\text { triangulares pedunculadas; preponderancia } \\
\text { de estrategias de minimización del tiempo } \\
\text { o expeditivas; predominio de materias } \\
\text { primas no locales (obsidianas) }\end{array}$ \\
\hline
\end{tabular}

Tabla 2. Resumen de los resultados principales del registro arqueofaunístico y lítico a lo largo del Holoceno en los conjuntos del sitio Alero Cuevas.

Table 2. Summary of the main results of the archaeofaunal and lithic record throughout the Holocene in the Alero Cuevas site assemblages. 
para el estudio de los procesos de interacción durante el Holoceno tardío. En el registro vegetal se detectaron fragmentos de astiles o partes de madera relacionadas con el enmangue de las puntas (Figura $3 \mathrm{~F}$ ). Los análisis llevados a cabo por la Dr. María Fernanda Rodríguez permitieron reconocer la presencia de Chusquea lorentziana Griseb, una caña maciza que crece en las yungas, a casi $300 \mathrm{~km}$ al este de Alero Cuevas. Otros vegetales como semillas y frutos, también provendrían de sectores más bajos como los valles mesotermales. Este es el caso de los restos de marlos de maíz $(n=10)$, chañar $(n=1)$ y algarrobo $(n=1)$ (Araya, 2017). Asimismo, se recuperaron 3 fragmentos de cuentas de valvas. A partir de los análisis del Dr. Sergio Miquel se determinó la presencia de un bivalvo marino (Figura $3 \mathrm{G}$ ), Clamys sp., procedente del Océano Pacífico, y Anodontites o Diplodon de agua dulce.

Por último, es importante destacar que se registraron fragmentos de cerámica $(n=20)$. En general, se trata de partes del cuerpo $(80,9 \%)$, con un predominio de tonalidades oscuras (castaño oscuro, gris y negro). El tratamiento de superficie mayoritario es el alisado $(57,1 \%)$, aunque también es alta la presencia de tiestos con bruñido y/o pulido (42,9\%). Esta capa está atravesada por una vasija entera depositada con la base hacia arriba, que corta la estratigrafía en un sector localizado entre las cuadrículas 3 y 4 (Figura $3 \mathrm{H}$ ). Su morfología corresponde a una olla globular, con un diámetro en la boca de $25 \mathrm{~cm}$ y una longitud de $40 \mathrm{~cm}$. Entre las características principales de esta vasija, se puede señalar el tratamiento alisado y la superficie de color gris con hollín. Este material carbonoso adherido a sus paredes puede asociarse con actividades de cocción en los diversos sectores de combustión que conforman este contexto.

\section{El sitio Alero Cuevas en el contexto de Pastos Grandes}

Si bien el sitio Alero Cuevas constituye la base cronológica de referencia para el estudio del cambio cultural a lo largo del Holoceno en Pastos Grandes, también se evidencian otros indicadores arqueológicos que resultan significativos para una perspectiva regional (Tabla 3).

Las quebradas de Santa Rosa y Las Cuevas, en Pastos Grandes, constituyen espacios con registro de ocupaciones humanas persistentes durante todo el Holoceno. De hecho, es en este sector donde se registró la única punta diagnóstica del Holoceno temprano en un contexto superficial de Pastos Grandes. Esta punta tiene una morfología triangular apedunculada de base recta, comparable a las de esta cronología en la capa F4 de Alero Cuevas. Por un lado, esta particularidad indicaría las dificultades propias de encontrar material correspondiente a las ocupaciones más antiguas de la región, dada la acción de procesos de formación que habrían afectado la preservación del registro de este período, especialmente en contextos de superficie. Sin embargo, la escasez de evidencia del Holoceno temprano reforzaría, a su vez, la hipótesis acerca de la existencia de ocupaciones humanas conformadas por grupos pequeños y móviles que dejarían pocos rastros visibles, salvo en espacios de uso recurrente como Alero Cuevas. Algo similar ocurre con la primera parte del Holoceno medio, ya que los indicadores de esta cronología tienen baja visibilidad arqueológica en Pastos Grandes. Igualmente, tanto en el sector de quebradas como en el fondo de cuenca, se han recuperado algunas puntas lanceoladas bifaciales grandes comunes en registros del Holoceno medio inicial, tal como se evidencia en la capa F3 de Alero Cuevas.

Por el contrario, a partir del Holoceno medio final se observa un notable aumento y diversificación de la señal antrópica en los distintos sectores de la cuenca de Pastos Grandes. Este aspecto podría relacionarse con un incremento de la densidad de población y del tamaño de los grupos que ocuparon el área (López, 2013). En particular, se ha registrado la proliferación en superficie de los artefactos lanceolados unifaciales sobre tecnología de hojas a lo largo de toda la cuenca (> 100 especímenes). En estratigrafía, estos artefactos se encuentran únicamente en la capa F2 de Alero Cuevas con fechas entre ca. 5106 AP y 4210 AP. En consecuencia, constituyen elementos tiempo-sensitivos para contextos de superficie. Este es el caso de un sitio con material lítico y ausencia de cerámica, localizado en el borde del salar de Pastos Grandes, denominado La Hoyada (López, 2008). Se trata de una concentración de artefactos con filos/bordes redondeados y pátina, sobre los que actuaron agentes y procesos erosivos en escala temporal larga. Entre ellos, la única clase diagnóstica de cronología está representada por los artefactos lanceolados unifaciales. Al igual que en la capa F2 de Alero Cuevas, también han sido hallados núcleos de hojas. Cabe señalar que los artefactos sobre hojas han sido confeccionados en materias primas locales como andesita y cuarcita. La asociación entre el uso de materias primas locales y la tecnología de hojas ha sido observada en la fuente de andesita de Pastos Grandes, denominada Picadero (López, 2008). En conjunto, la evidencia general de Pastos Grandes muestra cambios concordantes con el registro de la capa F2 de Alero Cuevas en el Holoceno medio final. En especial, se hace referencia a la proliferación de artefactos sobre hojas y al uso frecuente de materias primas locales.

Hacia finales del Holoceno medio y comienzos del Holoceno tardío se reconoce un hallazgo bioarqueológico particular, que reviste importancia por tratarse de los únicos restos humanos casi completos registrados hasta el momento en el área y por su localización en un contexto a cielo abierto (López y Miranda, 2007/2008). Al respecto, en su mayoría, los hallazgos bioarqueológicos correspondientes a esta cronología en la Puna se registraron en cuevas y aleros. En consecuencia, su recuperación en un sector 
del borde del salar de Pastos Grandes constituye una particularidad. Se identificaron 106 especímenes óseos, muchos de ellos completos, pertenecientes a un solo individuo humano de aproximadamente 30 años de edad y sexo masculino. A pesar de que se registró la mayor parte de las unidades anatómicas del esqueleto, incluso la mandíbula inferior con dientes, se destaca la ausencia del cráneo. El análisis por AMS permitió obtener una fecha radiocarbónica de $3738 \pm 46$ AP (López y Miranda, 2007/2008). Entre los atributos más llamativos del estudio de los restos humanos, se detectaron diversas marcas antrópicas de corte y machacado en costillas, vértebras y escápula, y un negativo de impacto sobre un metatarsiano. Además, se observó un artefacto pequeño de obsidiana incrustado en la epífisis distal del radio derecho (López, 2008; López y Miranda, 2007/2008). Todos estos indicadores constituyen posibles rastros de violencia sobre el individuo. En asociación con los restos humanos, se recuperó un artefacto lítico considerado ornamental, de morfología circular, con un orificio antrópico en el centro y bordes pulidos (López, 2008).

\begin{tabular}{|c|c|c|c|}
\hline Cronología & Sitio Alero Cuevas & $\begin{array}{l}\text { Otras evidencias } \\
\text { arqueológicas en la } \\
\text { cuenca de Pastos } \\
\text { Grandes }\end{array}$ & $\begin{array}{c}\text { Evidencias arqueológicas en } \\
\text { el contexto macrorregional } \\
\text { de la Puna argentina }\end{array}$ \\
\hline $\begin{array}{l}\text { Holoceno } \\
\text { temprano (ca. } \\
11000-8000 \\
\text { AP) }\end{array}$ & $\begin{array}{l}\text { Ocupaciones humanas } \\
\text { recurrentes y alta señal } \\
\text { antrópica; lugar central } \\
\text { (sensu Bettinger, 1991); } \\
\text { caza de camélidos } \\
\text { silvestres }\end{array}$ & $\begin{array}{c}\text { Evidencia } \\
\text { arqueológica aislada; } \\
\text { baja señal antrópica }\end{array}$ & $\begin{array}{c}\text { Ocupaciones humanas } \\
\text { puntuales en aleros y cuevas } \\
\text { y en algunos espacios a cielo } \\
\text { abierto; baja señal antrópica } \\
\text { en general; se postula la } \\
\text { presencia de grupos } \\
\text { pequeños con alta movilidad } \\
\text { residencial }\end{array}$ \\
\hline $\begin{array}{l}\text { Holoceno } \\
\text { medio inicial } \\
\text { (ca. } 8000- \\
6000 / 5500 \\
\text { AP) }\end{array}$ & $\begin{array}{l}\text { Ocupaciones humanas } \\
\text { menos recurrentes (más } \\
\text { puntuales); menor señal } \\
\text { antrópica; lugar central } \\
\text { (sensu Bettinger, 1991); } \\
\text { caza de camélidos } \\
\text { silvestres }\end{array}$ & $\begin{array}{c}\text { Evidencia } \\
\text { arqueológica aislada; } \\
\text { baja señal antrópica }\end{array}$ & $\begin{array}{c}\text { Ocupaciones humanas } \\
\text { puntuales; baja señal } \\
\text { antrópica general; se postula } \\
\text { el comienzo de un proceso } \\
\text { de intensificación en el uso } \\
\text { de los camélidos }\end{array}$ \\
\hline $\begin{array}{l}\text { Holoceno } \\
\text { medio final } \\
\text { (ca. } \\
6000 / 5500- \\
4000 / 3500 \\
\text { AP) }\end{array}$ & $\begin{array}{c}\text { Ocupaciones humanas } \\
\text { recurrentes y alta señal } \\
\text { antrópica; lugar central } \\
\text { (sensu Bettinger, 1991); } \\
\text { indicadores de procesos } \\
\text { de intensificación y } \\
\text { domesticación de } \\
\text { camélidos; cambio } \\
\text { tecnológico (proliferación } \\
\text { de hojas) y aumento de } \\
\text { materias primas locales }\end{array}$ & $\begin{array}{c}\text { Evidencia } \\
\text { arqueológica en } \\
\text { diversos sitios a cielo } \\
\text { abierto; alta señal } \\
\text { antrópica; presencia } \\
\text { de restos humanos } \\
\text { con signos de } \\
\text { violencia }\end{array}$ & $\begin{array}{l}\text { Ocupaciones humanas } \\
\text { recurrentes y aparición de } \\
\text { nuevos sitios; alta señal } \\
\text { antrópica; procesos de } \\
\text { intensificación y } \\
\text { domesticación de camélidos; } \\
\text { mayores tamaños de los } \\
\text { grupos humanos; indicadores } \\
\text { de reducción de la movilidad } \\
\text { residencial; tecnología de } \\
\text { hojas en la Puna de Salta y } \\
\text { Jujuy (ausencia en } \\
\text { Catamarca) }\end{array}$ \\
\hline $\begin{array}{l}\text { Holoceno } \\
\text { tardío } \\
\text { (centrado en } \\
\text { ca. } 2000-500 \\
\text { AP) }\end{array}$ & $\begin{array}{c}\text { Ocupaciones humanas } \\
\text { recurrentes y alta señal } \\
\text { antrópica; lugar central } \\
\text { (sensu Bettinger, 1991); } \\
\text { caza de camélidos } \\
\text { silvestres en el marco de } \\
\text { una economía basada en } \\
\text { el pastoreo; presencia de } \\
\text { cerámica; aumento de los } \\
\text { indicadores de interacción } \\
\text { macrorregional }\end{array}$ & $\begin{array}{l}\text { Evidencia } \\
\text { arqueológica en sitios } \\
\text { a cielo abierto; alta } \\
\text { señal antrópica; } \\
\text { proliferación de } \\
\text { estructuras } \\
\text { arquitectónicas; } \\
\text { presencia de cerámica }\end{array}$ & $\begin{array}{l}\text { Ocupaciones humanas } \\
\text { recurrentes y proliferación de } \\
\text { nuevos sitios con estructuras } \\
\text { arquitectónicas agrupadas; } \\
\text { alta señal antrópica; } \\
\text { diversidad de cerámica; } \\
\text { consolidación de nichos } \\
\text { económicos de producción } \\
\text { de alimentos; importancia de } \\
\text { la caza; menor movilidad } \\
\text { residencial; aumento de } \\
\text { interacción (e.g. tráfico } \\
\text { caravanero) }\end{array}$ \\
\hline
\end{tabular}

Tabla 3. Características comparativas de las ocupaciones humanas y la evidencia arqueológica a lo largo del Holoceno entre Alero Cuevas, otros registros de Pastos Grandes y el contexto macrorregional de la Puna argentina.

Table 3. Comparative characteristics of human occupations and archaeological evidence throughout the Holocene between Alero Cuevas, other records from Pastos Grandes, and the macro-regional context of the Argentine Puna. 
Los indicadores mencionados previamente muestran el aumento de la evidencia arqueológica en el área de Pastos Grandes durante el Holoceno medio final. De todas maneras, la visibilidad arqueológica de distintos indicadores se profundiza a lo largo del Holoceno tardío. En el sector de quebradas se ha observado la presencia de diversas estructuras arquitectónicas, mayormente circulares o subcirculares, algunas de las cuales han sido sondeadas y permitieron obtener fechas radiocarbónicas en el Holoceno tardío. Este es el caso del sitio Quebrada Alta, fechado en $1488 \pm 41$ AP, y el sitio Estructura Corral, con una datación de $859 \pm 45$ AP (López, 2008). En la excavación de Quebrada Alta se registraron algunos tiestos de cerámica similares a los de la capa $C_{1}$ de Alero Cuevas y artefactos líticos en obsidiana de Quirón, Tocomar y Ona. El fechado prehispánico más tardío de la cuenca (por fuera de Alero Cuevas) proviene del sitio Alero La Hoyada, en el sector del salar de Pastos Grandes $(680 \pm 29$ AP) (López, 2008). Tampoco debe soslayarse la presencia incaica en el área, tal como se registró en el volcán Quevar y sus cercanías (Ceruti, 2007). A esta evidencia se suma la recuperada en los últimos años en la cuenca de Ratones, a 80 km de Pastos Grandes, en donde se localizan los sitios Abra de Minas y Cueva Inca Viejo, con una intensa ocupación minero-ritual incaica (López et al., 2020).

\section{El sitio Alero Cuevas en el marco de la Puna argentina}

En esta sección se analiza la inserción de la información arqueológica de Alero Cuevas en el contexto macrorregional de la Puna argentina. La comparación permite caracterizar los procesos de cambio comunes y las diferencias regionales (Tabla 3 ).

En el Holoceno temprano (11000 - 8000 AP), se observa una relativa escasez de sitios arqueológicos a lo largo de la Puna argentina, aunque con una alta intensidad de ocupación en algunos abrigos rocosos (Muscio y López, 2016; Yacobaccio, 2021). En casos puntuales, como en Salar del Hombre Muerto, también se recuperaron distintas puntas triangulares apendunculadas en contextos de superficie a cielo abierto (Patané Aráoz et al. 2020). Estas puntas son frecuentes durante el Holoceno temprano a lo largo de los Andes centro sur, denominadas como patrón Tuina-Inca Cueva (Aschero, 1984; Núñez, 1992). Su presencia es compartida tanto en Alero Cuevas como en la mayoría de los sitios con fechados en esta cronología (Hocsman et al., 2012; Restifo, 2019). Aunque se detectan algunas variaciones métricas en la longitud, las puntas triangulares apedunculadas no tienen un patrón latitudinal o espacial particular (López y Restifo, 2017). En cambio, la mayor variabilidad entre sitios se encuentra en las frecuencias taxonómicas de los conjuntos arqueofaunísticos. En concreto, se observa una alta variación en los porcentajes NISP de camélidos y una mayor representación de roedores como los chinchíllidos (Yacobaccio, 2001, 2021). Por el contrario, en Alero
Cuevas el NISP \% de camélidos se mantiene constante en las distintas capas, con una alta proporción incluso en el Holoceno temprano.

En el Holoceno medio inicial (8000 - 6000/5500 AP), la señal antrópica disminuye fuertemente en distintos sectores de los Andes centro sur (Muscio y López, 2016; Núñez, 1992). De todas maneras, en los últimos años, se ha informado la presencia de sitios arqueológicos con fechados en esta cronología, incluyendo Alero Cuevas (López, 2008; Mondini et al., 2013; Pintar y Rodríguez, 2015; Yacobaccio et al., 2013). En general, se observan ciertos patrones comunes a nivel macrorregional, como la presencia de puntas bifaciales lanceoladas medianograndes y una alta representación de camélidos por sobre otros taxones en los restos arqueofaunísticos (Aschero y Martínez, 2001; Yacobaccio, 2001). En el promedio de sitios de la Puna argentina, los porcentajes de camélidos muestran un aumento importante en comparación con los conjuntos del Holoceno temprano (Yacobaccio, 2013). Esta característica podría indicar una tendencia hacia un proceso de intensificación a partir de comienzos del Holoceno medio. Sin embargo, otras variables arqueofaunísticas cuantificadas en los camélidos indican una continuidad respecto del Holoceno temprano. Este es el caso del perfil etario, con predominancia de elementos óseos correspondientes a maduros/adultos (López y Restifo, 2014). Una situación similar se refleja en Alero Cuevas entre el Holoceno temprano y el Holoceno medio inicial, con patrones persistentes no solo en el perfil etario sino también en la alta frecuencia de camélidos por sobre otros taxones. En el material lítico también se registran continuidades en la alta proporción de materias primas no locales (obsidianas) en relación con las locales. La diferencia principal se reconoce en los patrones morfológicos de las puntas, que en el Holoceno medio inicial comprenden principalmente formas lanceoladas/ elongadas. Esta variación es concordante con lo ocurrido en distintas áreas de la Puna argentina. En este punto, se debe remarcar que a partir del Holoceno medio se observa una diversificación macrorregional en las morfologías de las puntas, con nuevas variantes (Hoguin, 2014; López y Restifo, 2014).

En el Holoceno medio final (6000/5500 - 4000/3500 AP), la Puna argentina presenta un aumento en la frecuencia de sitios arqueológicos y una señal antrópica creciente a partir de esta cronología (Muscio y López, 2016). Estas características generales se reflejan también en una escala espacial de menor tamaño como la cuenca de Pastos Grandes. Se ha planteado que estas tendencias podrían indicar ocupaciones humanas de grupos más grandes en un ambiente altamente segmentado (López, 2008).

Los cambios observados en Alero Cuevas se corresponden con los registrados en diversos sitios de la Puna argentina. En los conjuntos arqueofaunísticos predominan los 
camélidos por sobre otros recursos, con una baja variabilidad regional (Yacobaccio, 2001). También se evidencia un aumento de huesos de camélidos no fusionados (subadultos) en el promedio de los sitios de las tierras altas del Noroeste argentino y del Norte de Chile, tal como ocurre en Alero Cuevas (López y Restifo, 2014). Este patrón se repite en otro sitio de la Puna de Salta, denominado Abrigo Pozo Cavado (López, 2013). En las capas de fines del Holoceno medio de este sitio, se observa un incremento notable de elementos óseos de subadultos. Entre ellos, se detectan nonatos/ neonatos $(25,7 \%)$ e inmaduros/juveniles (31,6\%), valores relativamente similares a los de Alero Cuevas (López y Orsi, 2019; Orsi, 2018). Otra similitud macrorregional ocurre con la presencia de especímenes de camélidos de tamaños grandes, que corresponderían a camélidos domesticados o en proceso de domesticación. En diversos contextos arqueológicos del Noroeste argentino, se ha postulado la relación de estos cambios osteométricos con procesos de domesticación de camélidos (Mengoni Goñalons y Yacobaccio, 2006). La información osteométrica de Alero Cuevas aporta a esta discusión de escala amplia.

En relación con el material lítico, también se evidencian variaciones importantes en comparación con períodos anteriores. En Alero Cuevas, el cambio más relevante se produce a partir de la proliferación de tecnología de hojas como forma base de los artefactos lanceolados unifaciales. Estos instrumentos, conocidos como Saladillo, se encuentran en distintas áreas de la Puna argentina, tanto en contextos de superficie como en capa (Fernández, 1983; Hoguin, 2014; López y Restifo, 2017; Restifo, 2015). Las fechas radiocarbónicas asociadas con estos artefactos corresponden a fines del Holoceno medio (ca. 5500-3500 AP) (López y Restifo, 2017). En esta cronología, la proliferación de hojas se encuentra espacialmente extendida en la Puna de Salta y Jujuy, pero se ha señalado su ausencia en la Puna de Catamarca (Aschero y Hocsman, 2011). Respecto del uso de materias primas, Alero Cuevas presenta características similares a las reconocidas en sitios de otras áreas de la Puna argentina. Se hace referencia al aumento o a la alta frecuencia de rocas locales en los materiales líticos del Holoceno medio final (Hoguin, 2014), lo cual se ha vinculado con procesos de reducción de la movilidad residencial. Cabe destacar que la asociación entre tecnología de hojas y materias primas locales es recurrente en distintos contextos de los Andes centro sur (Núñez, 1992). Finalmente, otro aspecto a considerar en los conjuntos líticos es la alta diversificación y variabilidad regional en las morfologías de puntas. En este marco, Alero Cuevas presenta algunas de las puntas replicadas macrorregionalmente, como las lanceoladas pequeñas (Restifo et al., 2019).

A partir del Holoceno tardío se reconoce una señal antrópica creciente, aunque con algunas oscilaciones (Muscio y López, 2016). Desde ca. 2000 AP en adelante, la frecuencia de sitios arqueológicos y los fechados radiocarbónicos se incrementan fuertemente.

Los conjuntos faunísticos de la Puna argentina muestran continuidades en torno a la representación mayoritaria de camélidos, comparativamente con otros taxones (Olivera, 1997; Yacobaccio, 2001). En cambio, el perfil etario indica una alta variabilidad local, con conjuntos en los que predominan elementos óseos de subadultos y otros con mayor frecuencia de adultos. De todas formas, se encuentra pendiente una comparación más precisa a nivel macrorregional. Por su parte, la osteometría refleja la importancia de las llamas, pero también se detectan diversos elementos óseos correspondientes a vicuñas (Olivera, 1997). Este es el caso de Alero Cuevas, donde el rol de la caza fue central aun en el marco de economías basadas en el pastoreo.

Los materiales líticos registran ciertos atributos compartidos en escala amplia, como la alta frecuencia de puntas triangulares pequeñas con pedúnculo. Sin embargo, se han evidenciado variaciones entre sitios en el uso de las materias primas, incluso dentro de las obsidianas. De hecho, se ha planteado la existencia de esferas de circulación de obsidianas diferenciadas entre el sector norte y sur de la Puna entre ca. 2200 - 500 AP, con presencia de espacios en que las mismas se superponían (Yacobaccio et al. 2004). En Alero Cuevas, y en la Puna de Salta en general, la variabilidad en el uso de fuentes de obsidianas incluye los sectores norte y sur (López, 2020). El aumento de los procesos de interacción podría estar relacionado con la importancia creciente del tráfico caravanero de llamas (Nielsen, 2013). Al respecto, en el sitio Cueva Inca Viejo de la Puna de Salta, se ha observado arte rupestre caravanero y una alta representación de materiales alóctonos en capa (López et al. 2020). A estos indicadores deben sumarse la diversidad de conjuntos cerámicos y elementos orgánicos frecuentes en los sitios correspondientes a estas cronologías. No es la intención profundizar en la variabilidad de estos registros, dado que escapa a los objetivos de este trabajo, pero es relevante destacar la existencia de profundos procesos de cambio ocurridos a lo largo del Holoceno tardío, relacionados con la consolidación de un nuevo nicho económico. Entre los indicadores de cambio con respecto a períodos anteriores, se observa una alta frecuencia y diversidad de estructuras arquitectónicas, lo cual representa nueva evidencia para comprender los patrones de uso del espacio y la disminución en la movilidad residencial (Tabla 3).

\section{Discusión y conclusiones}

Los resultados de la investigación arqueológica en Alero Cuevas se presentaron en perspectiva regional comparativa con el objetivo de analizar el aporte de la evidencia recuperada en este sitio a la discusión de diversos procesos ocurridos en la Puna argentina (Tabla 3). La comparación en escala amplia permitió detectar cambios concurrentes, principalmente en el Holoceno 
medio final (López y Restifo, 2014; Yacobaccio et al., 2017). Durante ese lapso (ca. 6000/5500 AP - 4000/3500 $A P)$, se han planteado procesos crecientes de aridización, segmentación ambiental y concentración de poblaciones humanas y recursos en parches distribuidos de manera heterogénea a lo largo de la Puna (Yacobaccio et al., 2017). Este marco habría sido propicio para el aumento del tamaño de los grupos en torno a los espacios productivos (López, 2008). Más generalmente, se ha propuesto una fase de crecimiento demográfico durante el Holoceno medio final, que habría impactado en los procesos de intensificación y domesticación de camélidos. Este planteo se basa tanto en el incremento de la señal antrópica de la Puna argentina y el Norte de Chile, medida por la cronología radiocarbónica y la frecuencia y aparición de nuevos sitios (Muscio y López, 2016), como por las evidencias de intensificación y domesticación de camélidos en diversos sitios andinos (López y Restifo, 2012; Mengoni Goñalons y Yacobaccio, 2006; Olivera, 1997; Yacobaccio, 2001, entre otros). En el caso de Alero de Cuevas, los conjuntos arqueofaunísticos y líticos expresan algunos de los cambios esperables a partir de estos procesos.

En los estudios faunísticos, las variaciones más relevantes para abordar estos temas se observan en el perfil etario y en las mediciones osteométricas de determinados especímenes óseos de camélidos. Respecto del perfil etario, se detecta un aumento de elementos óseos de subadultos, en especial neonatos, en la capa de fines del Holoceno medio. Este indicador es compartido con otros sitios a nivel regional, como Abrigo Pozo Cavado (López y Orsi, 2019). El incremento en la explotación de neonatos y otros camélidos subadultos podría interpretarse en el marco de la intensificación de estos recursos. En otras partes del mundo se han detectado procesos similares con otros taxones (e.g. Broughton, 1999).

Los análisis osteométricos en los huesos de camélidos también indican cambios relevantes para las problemáticas abordadas aquí. Estos estudios, tanto en Alero Cuevas como en otros sitios de la Puna argentina, presentan especímenes de camélidos de tamaños comparables a las Ilamas actuales y, en algunos casos, aún mayores (López y Restifo, 2014; Mengoni Goñalons y Yacobaccio, 2006). Este registro podría vincularse con los procesos de domesticación de camélidos ocurridos durante el Holoceno medio final en los Andes centro sur (Mengoni Goñalons y Yacobaccio, 2006; Yacobaccio, 2001). Lamentablemente, no se puede profundizar al respecto, dado que las muestras osteométricas en los sitios de la Puna argentina para esta cronología son todavía pequeñas. Tampoco se puede determinar en qué escala espacial se desencadenaron estos procesos y, en consecuencia, qué rol tuvo la Puna de Salta (López y Orsi, 2019).

Al mismo tiempo, durante el Holoceno medio final, se consolidaron cambios tecnológicos asociados con la proliferación de hojas como forma base de los artefactos lanceolados unifaciales "Saladillo" (López y Restifo, 2014). Se ha planteado el rol eficiente de la tecnología de hojas para maximizar el rendimiento de los recursos (sensu Bousman, 1993), principalmente en el procesamiento de camélidos, ante un aumento de la demanda energética como parte de procesos de intensificación (López y Restifo, 2012). Concretamente, el cambio tecnológico representado por las hojas se correspondería con estrategias de maximización de recursos, más complejas y con mayor inversión de energía (Bousman, 1993), que permiten obtener formas similares de fácil reemplazo y filos largos con alto potencial de uso. Procesos semejantes, que vinculan la expansión de la tecnología de hojas con un marco de intensificación, han sido estudiados en otras partes del mundo (e.g. Quintero y Wilke, 1995). En cambio, la tecnología del Holoceno temprano del sitio Alero Cuevas muestra una baja inversión de energía, que podría relacionarse con estrategias de minimización del tiempo o expeditivas (Restifo, 2019), lo cual es compatible con la presencia de grupos humanos muy móviles y pequeños en un marco de menor segmentación de parches y mayor disponibilidad de recursos (Yacobaccio, 2021).

Por el contrario, durante el Holoceno medio final se habrían desarrollado procesos de reducción de la movilidad residencial (Yacobaccio, 2021), que, en el caso de Alero Cuevas, podrían estar indicados por el incremento de materias primas líticas locales. Los cambios en la movilidad en este período serían consecuencia de la alta segmentación ambiental y la concentración de los recursos (Yacobaccio, 2021). Incluso, es posible que estas características ambientales hubieran llevado a un aumento de la competencia por las tierras y los nutrientes necesarios para la subsistencia (López, 2008). Actualmente, no se cuenta con información suficiente para seguir profundizando en estos aspectos, aunque no puede ser soslayado el hallazgo de un esqueleto humano con signos de violencia en el salar de Pastos Grandes fechado en este lapso y la variabilidad regional en el uso de las hojas (e.g. la ausencia en Catamarca). Para abordar este tema es necesario aumentar los muestreos que permitan obtener nuevos registros bioarqueológicos del Holoceno medio final.

Hacia el Holoceno tardío, los cambios se profundizaron en función de un nuevo nicho económico. La combinación del pastoreo y la caza, como ocurrió en Pastos Grandes, puede ser considerada una estrategia adversa al riesgo (López, 2008). En esta situación no habría sido necesaria la continuidad de tecnologías líticas complejas como las hojas. La mayor inversión de energía de los grupos habría estado relacionada con la confección y/u obtención de nuevas tecnologías como la cerámica, y con la construcción y mantenimiento de estructuras arquitectónicas vinculadas con este nuevo nicho 
económico (e.g. corrales). En Pastos Grandes, este cambio se encuentra representado en sitios como Quebrada Alta y Estructura Corral. Si bien la proliferación de estructuras arquitectónicas suele ser considerada una evidencia de menor movilidad residencial, los procesos de interacción habrían aumentado a partir de mecanismos como el tráfico caravanero (Nielsen, 2013). En el caso de Alero Cuevas, se detecta una alta variabilidad de materiales alóctonos provenientes de grandes distancias. Estos indicadores constituyen la demostración de que se incrementaron los procesos de interacción, aun en contextos de menor movilidad residencial.

Para finalizar, se hace foco en las discontinuidades y continuidades en el uso del alero. En relación con las discontinuidades, se han observado extensos lapsos en los cuales no parece haberse ocupado el sitio. Más precisamente, los lapsos discontinuos más amplios se reconocen hacia finales del Holoceno temprano y comienzos del Holoceno medio (entre la capa F4 y la capa F3), durante el Holoceno medio (entre las capas F3 y F2), y a comienzos del Holoceno tardío (entre las capas F2 y (1). Sin embargo, estas discontinuidades deben considerarse con prudencia aún, debido a la presencia de capas de baja potencia en sectores específicos del alero, aún no datadas. Este es el caso de algunas capas finas entre F2 y C1, que podrían aumentar la cronología de comienzos del Holoceno tardío en sectores acotados de las cuadrículas 1 y 2 . Además, debe considerarse que el uso del espacio dentro los abrigos rocosos no es homogéneo a lo largo del tiempo, por lo cual pudo haber ocurrido que determinados sectores hayan sido ocupados en una cronología y no en otra. Con esto se busca señalar la necesidad de seguir incrementando las excavaciones y los fechados radiocarbónicos en Alero Cuevas, con el objetivo de esclarecer si hubo discontinuidades en la secuencia arqueológica. Para tal fin es fundamental profundizar la variabilidad en el uso del espacio intrasitio.

De todas formas, sería esperable la existencia de discontinuidades, tal como se detecta en el uso de aleros y cuevas en la Puna argentina en general. En muchos sitios se han visto secuencias de amplia profundidad temporal que se interrumpen en distintos lapsos (e.g. Pintar, 2014). En consecuencia, también Alero Cuevas pudo haber sido utilizado recurrentemente en determinados períodos y abandonado en otros. En este caso, habría que analizar la posibilidad de un desarrollo de diversos circuitos de movilidad y uso del espacio, en algunos de los cuales Alero Cuevas habría estado incluido, mientras que en otros no. Más claramente, es probable que ante determinados cambios ecológicos, sociales y/o en la dinámica de movilidad y uso del espacio, este sitio dejara de usarse recurrentemente o incluso se abandonara temporalmente. Para profundizar en este aspecto, como se dijo anteriormente, se debe seguir aumentando el área excavada dentro del alero y la cronología disponible.

Con respecto a las continuidades, no se pretende señalar un uso del sitio sin interrupciones o abandonos temporales, sino determinadas estrategias comunes en los lapsos en los cuales ha sido ocupado. Se hace referencia a la utilización de este sitio como un lugar central (sensu Bettinger, 1991), estratégicamente ubicado para acceder a los recursos principales del área. Entre estos recursos, se puede destacar el agua que fluye por las quebradas a partir del deshielo de los nevados de Pastos Grandes, y la abundancia de alimento cárnico proveniente de los taxones de mayor rendimiento en la región, los camélidos silvestres.

La continuidad en el uso del alero para estos propósitos queda evidenciada a partir de la importancia de la actividad cazadora, incluso después de la consolidación del pastoreo como estrategia económica central del nicho a lo largo del Holoceno tardío. En las distintas capas del sitio, además de predominar los camélidos en las frecuencias arqueofaunísticas, la osteometría permitió distinguir una mayor representación de elementos óseos correspondientes a camélidos silvestres, asociados con distintas clases de puntas. La recurrencia de sectores de combustión (posiblemente fogones) y una amplia diversidad de instrumentos líticos, desechos de talla y abundantes restos arqueofaunísticos, muestran el uso persistente del alero en escala de largo plazo. Estos materiales, sumados a la localización en un sector óptimo para la ocupación humana dentro del área, refuerzan el rol de este espacio como un lugar central desde el que se obtenían los recursos necesarios para la subsistencia. A estas ventajas, debe sumarse la posibilidad de refugio, dada la escasez de abrigos similares disponibles para la habitabilidad.

Entre las actividades realizadas en este espacio, se pudo inferir el procesamiento y consumo de alimentos (principalmente camélidos), y trabajos con el material lítico para la formatización final de instrumentos (abundancia de desechos de talla de tamaños pequeños y muy pequeños). Los indicadores arqueológicos permiten señalar un uso doméstico del sitio, aún más notable en el Holoceno tardío, tal como lo refleja la recuperación de una olla de cerámica vinculada con la cocción de alimentos y el acondicionamiento del suelo con una camada de gramíneas. Si bien no se pudo determinar el uso anual del sitio, sí fue posible establecer la ocupación veraniega en toda la secuencia, dada la presencia de elementos óseos de camélidos neonatos.

Como perspectiva a futuro, se necesita seguir profundizando en el análisis de distintas líneas de investigación que permitan responder los diversos interrogantes esbozados en este trabajo.

Bella Vista, 23 de junio de 2021 


\section{Agradecimientos}

A la memoria del gran cacique Nicolás Morales, a todos los pobladores de Pastos Grandes, al Museo de Antropología de Salta, a los distintos participantes de las campañas de investigación y análisis de laboratorio, a los Dres. Federico Restifo, Juan Pablo Orsi, María Fernanda Rodríguez y Sergio Miquel, y al CONICET.

\section{Bibliografía}

Araya, S. (2017). Análisis arqueobotánico de tres sitios ubicados en la Puna de Salta (Argentina) datados entre 2000-600 años AP. Cuadernos del Instituto Nacional de Antropología y Pensamiento Latinoamericano - Series Especiales, 4(3), pp. 51-61. http://sedici.unlp.edu.ar/ handle/10915/79006

Aschero, C. (1983). Ensayo para una clasificación morfológica de artefactos líticos aplicada a estudios tipológicos comparativos. Buenos Aires, Ms.

Aschero, C. (1984). El sitio ICC-4. Un asentamiento precerámico en la quebrada de Inca Cueva (Jujuy, Argentina). Estudios Atacameños, 7, 53-60. https://doi. org/10.22199/S07181043.1984.0007.00006

Aschero, C. y Martínez, J. (2001). Técnicas de caza en Antofagasta de la Sierra, Puna Meridional Argentina. Relaciones de la Sociedad Argentina de Antropología, 26, 215-241. http://sedici.unlp.edu.ar/handle/10915/20553

Aschero, C. y Hocsman, S. (2011). Arqueología de las ocupaciones cazadoras-recolectoras de fines del Holoceno medio de Antofagasta de la Sierra (Puna Meridional Argentina. Chungara, Revista de Antropología Chilena, 43, 393-411. http://dx.doi.org/10.4067/S071773562011000300005

Bettinger, R. (1991). Hunter-gatherers: Archaeological and Evolutionary Theory, New York/London: Plenum Press.

Bousman, B. (1993). Hunter-gatherer adaptations, economic risk and tool design. Lithic Technology, 18, 59-86. https://www.jstor.org/stable/23272865

Broughton, J. (1999). Resource depression and Intensification During the Late Holocene, San Francisco Bay. Berkeley, Los Angeles, London: University of California Press.

Ceruti, C. (2007). Panorama de los santuarios inca de alta Montaña en Argentina. Arqueología y Sociedad, 1-18. https://doi.org/10.15381/arqueolsoc.2007n18.e13157

Fernández, J. (1983). Río Grande. Exploración de un centro precerámico en las altas montañas de Jujuy, Argentina.
Ampurias, 45/46, 54-83.

Hocsman, S. (2006). Producción Lítica, Variabilidad y Cambio en Antofagasta de la Sierra ca. 5500-1500 AP (Tesis de doctorado). Facultad de Ciencias naturales y Museo, Universidad Nacional de La Plata. http://sedici. unlp.edu.ar/handle/10915/4462

Hocsman, S., Martínez, J., Aschero, C. y Calisaya, A. (2012). Variability of triangular non-stemmed projectile points of early hunter-gatherers of the Argentinean Puna. Current Research in the Pleistocene (Special Edition), 63-68.

Hoguin, R. (2014). Secuencia cronológica y tecnología lítica en la Puna Seca y Salada de los Andes Centro-Sur para el Holoceno temprano y medio a través del ejemplo de Susques. Relaciones de la Sociedad Argentina de Antropología, XXXIX (2), 333-364. http://sedici.unlp.edu. ar/handle/10915/46658

López, G. (2008). Arqueología de Cazadores y Pastores en Tierras Altas. Ocupaciones Humanas a lo Largo del Holoceno en Pastos Grandes, Puna de Salta, Argentina. Oxford: BAR International Series 1854, South American Archaeology Series No. 4.

López, G. (2013). Ocupaciones humanas y cambio a lo largo del Holoceno en abrigos rocosos de la Puna de Salta, Argentina: Una perspectiva regional. Chungara, Revista de Antropología Chilena, 45 (3), 411-426. http://dx.doi. org/10.4067/S0717-73562013000300004

López, G. (2020). Macro-regional interaction processes in the south-central Andes along the Holocene (ca. 10000500 BP): obsidian circulation, cultural transmission and evidence of allochthonous materials at archaeological sites in the Puna of Salta, North-western Argentina. Journal of Archaeological Science Reports, 29, 1-11. https://doi.org/10.1016/j.jasrep.2019.102187

López, G. y Miranda, P. (2007/2008). El "muerto" del salar: Descripción de un hallazgo bioarqueológico a cielo abierto datado en ca 3700 AP en el borde del salar de Pastos Grandes, Puna de Salta. Revista Arqueología, 14, 199-215.

López, G. y Orsi, J. (2019). Intensificación y domesticación de camélidos en los Andes Centro Sur: variabilidad y procesos de cambio en la Puna de Salta, Argentina. Cuadernos del Instituto Nacional de Antropología y Pensamiento Latinoamericano - Series especiales, 7 (2), 149-159. http://ppct.caicyt.gov.ar/index.php/cinapl-se/ article/view/17322/45454575769579

López, G. y Restifo, F. (2012). Middle Holocene intensification and domestication of camelids in north Argentina, as tracked by zooarchaeology and lithics. 
Antiquity, 86, 1041-1054. https://doi.org/10.1017/ S0003598X00048237

López, G. y Restifo, F. (2014). Procesos de diversificación, intensificación y domesticación durante el Holoceno en las tierras altas del norte de Argentina y Chile: aportes desde la Puna de Salta. Comechingonia, 18 (2), 95-116. https://doi.org/10.37603/2250.7728.v18.n2.18156

López, G. y Restifo, F. (2017). El sitio Alero Cuevas, Puna de Salta, Argentina: secuencia de cambio en artefactos líticos y resolución cronológica macrorregional durante el Holoceno temprano y medio. Chungara, Revista de Antropología Chilena 49 (1), 49-63. http://dx.doi. org/10.4067/S0717-73562017005000005

López, G., Coloca, F., Orsi, J., Araya, S., Seguí, S., Rosenbusch, M. y Solá, P. (2020). Ocupación incaica en Cueva Inca Viejo y Abra De Minas, Puna de Salta, Argentina: Minería de turquesa y prácticas rituales. Estudios Atacameños, 66, 49-82. https://doi. org/10.22199/issn.0718-1043-2020-0043

Martínez, J. (2003). Ocupaciones humanas tempranas y tecnología de caza en Antofagasta de la Sierra, Puna meridional argentina (10000-7000 AP). Cazadores Recolectores del Cono Sur, 2, 129-150.

Mengoni Goñalons, G. y Yacobaccio, H. (2006), "The Domestication of South American Camelids: A View from the South-Central Andes", En Zeder, M., Bradley, D.G., Emshwiller, M. y Smith, B. (Editores), Documenting Domestication: New Genetic and Archaeological Paradigms (pp. 228-244). London: University of California Press.

Mercuri, C. (2014). Conjuntos líticos formativos del sitio Alero Cuevas (Salta, Argentina): puesto de caza de pastores de altura. Intersecciones en Antropología, 15, 251-264. http://www.scielo.org.ar/pdf/iant/v15n1/ v15n1a18.pdf

Mercuri, C. y Restifo, F. (2014). Application of physicchemical and macroscopic methods to lithic artifact studies from Alero Cuevas site (Salta, República Argentina): a complementary approach. En Kligmann, D. y Morales, M. (Editores), Physical, Chemical and Biological Markers in Argentine Archaeology: Theory, Methods and Applications (pp. 27-38). Oxford: BAR International Series, vol. 2678, Archaeopress.

Mondini, M., Martínez, J., Pintar, E. y Reigadas, M. (2013). Middle Holocene foraging, mobility and landscape use in the southern Argentinean Puna: Hunter gatherers from Antofagasta de la Sierra, Catamarca, Argentina. Quaternary International, 307, 66-73.

https://doi.org/10.1016/j.quaint.2013.05.015
Moreno, E. (2011). Tecnología de caza en Antofalla, Departamento de Antofagasta de la Sierra, Catamarca. Revista del Museo de Antropología, 4, 17-32. https://doi. org/10.31048/1852.4826.v4.n1.5498

Muscio, H. y López, G. (2016). Radiocarbon dates and anthropogenic signal in the South-Central Andes (12,500 - 600 cal. years BP). Journal of Archaeological Science, 65, 93-102. http://dx.doi.org/10.1016/j.jas.2015.11.007

Nielsen, A. (2013). Circulating objects and the constitution of South Andean Society (500 BC-1550 AD). En Hirth, K. y Pillsbury, J. (Editores), Merchants, Markets, and Exchange in the Pre-columbian World (pp. 389-418). Washington: Dumbarton Oaks.

Núñez, L. (1992). Ocupación arcaica en la Puna de Atacama: secuencia, movilidad y cambio. En B. Meggers (editora), Prehistoria Sudamericana. Nuevas perspectivas (pp. 283-307). Washington: Taraxacum.

Olivera, D. (1997). La importancia del recurso camelidae en la puna de Atacama entre 10.000 y 500 años AP. Estudios atacameños, 14, 29-41. https://doi. org/10.22199/S07181043.1997.0014.00004

Olivera, D. (2012). El Formativo en los Andes del sur: la incorporación de la opción productiva. En Haro, M., Rocchietti, A., Runcio, M., Hernández de Lara y Fernández, V. (Editores), Interculturalidad y ciencias: Experiencias desde América latina (pp. 15 - 49). Buenos Aires, Editorial Centro de Investigaciones precolombinas.

Orsi, J. (2018). Explotación de recursos faunísticos y procesos de cambio en el uso de los camélidos en la Puna de Salta (ca. 10.000-2.500 años AP): Análisis del registro arqueofaunístico de los sitios Alero Cuevas y Abrigo Pozo Cavado (Tesis de Doctorado). Facultad de Filosofía y Letras, Universidad de Buenos Aires.

Patané Aráoz, C., Leale, B. y Piraino, J. (2020). Estudio de un sitio a cielo abierto de cazadores recolectores en el salar del Hombre Muerto (zona limítrofe de las provincias de Salta y Catamarca). Una contribución a la arqueología del Holoceno temprano en la Puna del Noroeste de Argentina. Andes, 31(2), 1-36. http://www.scielo.org.ar/ pdf/andes/v31n2/v31n2a01.pdf

Pintar, E. (2014). Continuidades e hiatos ocupacionales durante el Holoceno Medio en el borde oriental de la Puna Salada, Antofagasta de la Sierra, Argentina. Chungara Revista de Antropología Chilena, 46, 51-71. http://dx.doi. org/10.4067/S0717-73562014000100004

Pintar, E. y Rodríguez, M. (2015). Understanding foraging radius and mobility in a high desert". Journal of Archaeological Science, 59, 142-158. http://dx.doi. org/10.1016/j.jas.2015.04.013 
Quintero, L. y Wilke, P. (1995). Evolution and economic significance of naviform core and blade technology in the southern Levant. Pal'eorient, 21, 17-33. https://www. persee.fr/doc/paleo_0153-9345_1995_num_21_1_4607

Ratto, N. (2006). El Arcaico y el Formativo en la Puna de Chaschuil a través del diseño de las puntas líticas (Departamento Tinogasta, Catamarca). Cazadores Recolectores del Cono Sur, 1, 93-110.

Restifo, F. (2013), Tecnología lítica en la Puna de la Provincia de Salta a lo largo del Holoceno temprano y medio: Patrones de variación y procesos de cambio (Tesis de doctorado). Facultad de Filosofía y Letras, Universidad de Buenos Aires.

Restifo, F. (2015). Tecnología de hojas líticas en tierras altas andinas: perspectivas desde la puna de la provincia de Salta (Argentina). Estudios Atacameños, 51, 33-51. http://dx.doi.org/10.4067/S0718-10432015000200004

Restifo, F. (2019). Discussing the Peopling of the Puna of Salta (Argentine Andes) from the Lithic Evidence: The Alero Cuevas Site Study Case. PaleoAmerica, 5 (4), 392402. https://doi.org/10.1080/20555563.2019.1697128

Restifo, F., Carbonelli, J. y Agnolin, A. (2019). Puntas de proyectil de puna y valles mesotermales del Noroeste argentino en perspectiva comparativa: los casos de la cuenca de Pastos Grandes (Departamento de los Andes, Salta) y el Valle de Santa María (Catamarca) como aporte para la arqueología de cazadores recolectores. Andes, 20 (2), 1-28. http://www.icsoh.unsa.edu.ar/numeros-andes/ andes-2019-30-vol-2/

Yacobaccio, H. (2001). Cazadores complejos y domesticación de camélidos. En Mengoni Goñalons, G., Olivera, D. y Yacobaccio, H. (Editores), El Uso de los Camélidos a través del Tiempo (pp. 261-281). Buenos Aires: Ediciones del Tridente.

Yacobaccio, H. (2013). Towards a Human Ecology for the Middle Holocene in the Southern Puna. Quaternary International, 307, 24-30. http://dx.doi.org/10.1016/j. quaint.2012.08.2109

Yacobaccio, H. (2021). The domestication of South American camelids: a review. Animal Frontiers, 11 (3), 43-51. https://doi.org/10.1093/af/vfaa065

Yacobaccio, H. y Vilá, B. (2002). Condiciones mecanismos y consecuencias de la domesticación de camélidos. Estudios Sociales del NOA, 3, 4-27.

Yacobaccio, H., Escola, P., Pereyra, F., Lazzari, M. y Glascock, M. (2004). Quest for ancient routes: obsidian sourcing research in Northwestern Argentina. Journal of Archaeological Science, 31, 193-204. https://doi. org/10.1016/j.jas.2003.08.001

Yacobaccio, H., Morales, M., Solá, P., Samec, C., Hoguin, R. y Oxman, B. (2013). Mid-Holocene occupation of the Dry Puna in NW Argentina: evidence from the Hornillos 2 rockshelter. Quaternary International, 307, 38-49. https:// doi.org/10.1016/j.quaint.2012.09.028

Yacobaccio, H., Morales, M. y Hoguin, R. (2017). Habitats of ancient hunter-gatherers in the Puna: resilience and discontinuities during the Holocene. Journal of Anthropological Archaeology, 46, 92-100. http://dx.doi. org/10.1016/j.jaa.2016.08.004 